\title{
STUDY OF BIOCHEMICAL AND HEMATOLOGICAL MARKERS IN PATIENTS DIAGNOSED WITH BASAL CELL CARCINOMA
}

\section{Gurgas Leonard', Rosoiu Natalia'12, Chirila Sergiu', Hangan Tony'}

${ }^{1}$ Faculty of Medicine, University "Ovidius" of Constanta

${ }^{2}$ Academy of Romanian Scientists, Bucharest, Romania

\begin{abstract}
In recent years, numerous scientific research papers have focused on the analysis of immunological, biochemical, ultrastructural, molecular and genetic factors that govern the clinical aspects of basal cell carcinomas. This retrospective study was carried out in the Clinical Department of Dermatovenerology at the County Emergency Clinical Hospital "Sf. Apostol Andrei", Constanta. The research included a total of 140 patients treated in the clinic, with a diagnosis of basal cell epithelioma. We analyzed several biochemical and hematological markers including creatinine, male HDL cholesterol, female HDL cholesterol, LDL cholesterol, urea, serum glucose. More than half of patients with BCC present data of possible hepatic impairment and high atherogenic risk.
\end{abstract}

Keywords: Urea, cholesterol, creatinine, basal cell carcinoma

\section{Introduction}

The epithelial organization contains, from the surface to the inside: the epidermis (together with associated annexes, pilosebaceous follicles, and sweat glands), the dermis, separated from the epidermis by the dermo-epidermal junction, and the hypoderm (1). The epidermis is composed of the outermost layers of the skin cells. It is a stratified squamous epithelium consisting of basal and differentiated suprabasal proliferative keratinocytes that act as a major barrier against an intimate environment by preventing pathogens, which makes the skin a natural barrier against infections (2). Human skin protects the body as a barrier to various environmental threats and has to face a huge amount of germs as well as potential pathogens (3). The base substance is made up of macromolecules that fill the space between the fibers and the dermal cells and is more abundant in the papillary dermis and around the cutaneous supplements. It is not visible in normal histological sections. Biochemical consists of glycoproteins and proteoglycans (hyaluronic acid, dermatan sulfate, chondroitin4-sulfate, fibronectin, tenascin, etc.) that interact with the fibrous and cellular components of the dermis (4).

In recent years, numerous scientific research papers have focused on the analysis 
of immunological, biochemical, ultrastructural, molecular and genetic factors that govern the clinical aspects of basal cell carcinomas. Although changes in the lipid profile of patients with basal cell carcinoma (BCC) are still irrelevant (5), this study aims to investigate certain risk factors for the onset of BCC associated with hematological markers that can cause diseases that may favor an increased risk of occurrence of more frequent cancers (6). In addition, the systematic existence of many globular formations at the periphery of the tumor, constituted by an amorphous substance, limits the peripheral extension of the tumor by fitting the junction with the normal skin tissue, which explains their slow evolution in years (7), and might be related to their recurrence (8).

\section{Materials and method}

The retrospective study was carried out in the Clinical Department of Dermatovenerology at the County Emergency Clinical Hospital "Sf. ApostolAndrei"inConstanţa, between 01.01.2017 - 31.12.2017. The research included 140 patients treated in the clinic with basal cell epitheliomas. We have analyzed several biochemical and haematological markers of which: creatinine, HDL cholesterol, LDL cholesterol, urea serum glucose. The data was added into the database using the Microsoft Access application and the processing was performed using Microsoft Excel. We used the Chi-square test to determine the statistical significance of association between the types of indicators evaluated, and for comparison $t$ test and Anova test, depending on the number of independent variables. The threshold of statistical significance chosen is $p \leq 0.05$.

\section{Results}

With regard to gender distribution of the analyzed cases, of the 140 cases, 44 (31\%) were women and 96 (69\%) were males (Table $1)$. The proportion of men with $\mathrm{BCC}$ is higher than that of women and also the fac. It may be caused by their prolonged outdoor activities under UV rays, certain categories (farmers, fishermen) carcinomas significance becomes even occupational disease $(9,10)$. Further, we compared patients based on the environment they are coming from (urban or rural). In this case we observe the fact that $51 \%$ of the patients come from rural area. This represents an important environmental aspect, as it differs significantly form the population distribution of the county, where around $70 \%$ of the people live in urban areas.

Regarding the age of the patients, most of the patients $(27 \%)$ belong to the 70 to 79 years age group. The tumor size was less than $1 \mathrm{~cm}$ in $35 \%$ of the cases, 1 to $2 \mathrm{~cm}$ in $40 \%$ of the cases, $2-3 \mathrm{~cm}$ around $40 \%$ and more than $3 \mathrm{~cm}$ for $5 \%$ of the patients.

Table 1 Distribution of the patients

\begin{tabular}{|c|c|c|c|}
\hline \multirow{2}{*}{\multicolumn{2}{|c|}{\begin{tabular}{|l|} 
\\
Total
\end{tabular}}} & Number & Percentage \\
\hline & & 140 & \\
\hline \multirow{2}{*}{ Gender } & Male & 96 & 69 \\
\hline & Female & 44 & 31 \\
\hline \multirow{2}{*}{ Environment } & Urban & 69 & 49 \\
\hline & Rural & 71 & 51 \\
\hline \multirow{5}{*}{ Age Group } & $<50$ & 20 & 14 \\
\hline & $50-59$ & 27 & 19 \\
\hline & 60-69 & 27 & 19 \\
\hline & 70-79 & 38 & 27 \\
\hline & 880 & 28 & 20 \\
\hline \multirow{4}{*}{ Tumor size } & $<1 \mathrm{~cm}$ & 49 & 35 \\
\hline & $1-2 \mathrm{~cm}$ & 56 & 40 \\
\hline & $2-3 \mathrm{~cm}$ & 28 & 20 \\
\hline & $P 3 \mathrm{~cm}$ & 7 & 5 \\
\hline
\end{tabular}

Table 2 Creatinine

\begin{tabular}{|c|c|c|c|c|}
\hline \multicolumn{2}{|c|}{ Creatinine } & Mean & \begin{tabular}{|c|} 
Standard \\
Deviation
\end{tabular} & $\mathrm{P}$ \\
\hline \multirow{2}{*}{ Gender } & Male & 0.70 & 0.02 & \multirow{2}{*}{0.53} \\
\hline & Female & 0.70 & 0.02 & \\
\hline \multirow{2}{*}{ Environment } & Urban & 0.70 & 0.02 & \multirow{2}{*}{0.36} \\
\hline & Rural & 0.70 & 0.02 & \\
\hline \multirow{5}{*}{ Age Group } & $<50$ & 0.696 & 0.027 & \multirow{5}{*}{0.38} \\
\hline & $50-59$ & 0.701 & 0.024 & \\
\hline & 60-69 & 0.697 & 0.020 & \\
\hline & $70-879$ & 0.708 & 0.033 & \\
\hline & $>80$ & 0.703 & 0.025 & \\
\hline \multirow{4}{*}{ Tumor size } & $<1 \mathrm{~cm}$ & 0.703 & 0.023 & \multirow{4}{*}{0.8} \\
\hline & $1-2 \mathrm{~cm}$ & 0.699 & 0.026 & \\
\hline & $2-3 \mathrm{~cm}$ & 0.705 & 0.037 & \\
\hline & $P 3 \mathrm{~cm}$ & 0.702 & 0.020 & \\
\hline
\end{tabular}

We applied t test or Anova to determine the statistical significance of the difference observed for the creatinine level. Mean values and standard 
deviation, by subgroup and $\mathrm{p}$ values are available in table 2 . We observed no statistically significant difference for any of the analyzed variables, such as gender, environment, age group or tumor size.

Applying the test $\mathrm{t}$ in Table $3, \mathrm{p}=0.63$, the H0 hypothesis is valid, sex has no effect on the urea indicator. For $p=0.48$, the environment does not influence the urea indicator. Applying the Anova test in the analysis of age influence on this indicator, the probability $p=0.8 \mathrm{H} 0$ is accepted, so there is no statistically significant influence. Also, the tumor size analysis shows no influence on the urea indicator, $\mathrm{p}=0.88$.

Table 3 Urea

\begin{tabular}{|c|c|c|c|c|}
\hline \multicolumn{2}{|c|}{ Urea } & Mean & $\begin{array}{l}\text { Standard } \\
\text { deviation }\end{array}$ & $\mathrm{P}$ \\
\hline \multirow{2}{*}{ Gender } & Male & 42.41 & 6.66 & \multirow{2}{*}{0.63} \\
\hline & Female & 41.83 & 6.38 & \\
\hline \multirow{2}{*}{ Environment } & Urban & 41.98 & 7.72 & \multirow{2}{*}{0.48} \\
\hline & Rural & 42.46 & 5.85 & \\
\hline \multirow{5}{*}{ Age Group } & $<50$ & 43.14 & 1.499 & \multirow{5}{*}{0.80} \\
\hline & $50-59$ & 42.37 & 1.261 & \\
\hline & 60-69 & 42.83 & 1.239 & \\
\hline & \begin{tabular}{|l|}
$70-79$ \\
\end{tabular} & 42.12 & 1.084 & \\
\hline & $>80$ & 41.00 & 1.269 & \\
\hline \multirow{4}{*}{ Tumor size } & $<1 \mathrm{~cm}$ & 42.57 & 6.702 & \multirow{4}{*}{0.88} \\
\hline & $1-2 \mathrm{~cm}$ & 41.67 & 6.877 & \\
\hline & $2-3 \mathrm{~cm}$ & 42.63 & 6.000 & \\
\hline & $>3 \mathrm{~cm}$ & 42.63 & 6.183 & \\
\hline
\end{tabular}

Figure 1 shows that most urea values do not exceed the normality threshold (84\%). However, there is a $16 \%$ above this limit.

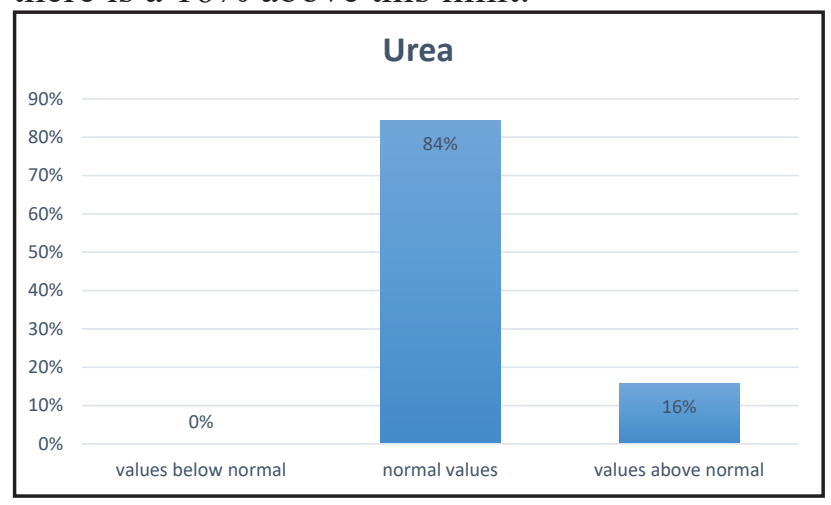

Figure 1 Analysis of urea indicator

HDL Cholesterol had an average value of $54.4 \mathrm{mg} / \mathrm{dl}$ for males and a $53 \mathrm{mg} / \mathrm{dl}$ for women. Still, the difference was not staitstically significant $(\mathrm{p}=0.29)$. (Table 4) In all other comparisons, there was no statistically significant difference $(p=0.91$ for environment, $p=0.56$ for age group, $\mathrm{p}=0.47$ for tumor size).

Table 4 HDL cholesterol

\begin{tabular}{|c|c|c|c|c|}
\hline \multicolumn{2}{|c|}{ HDL Cholesterol } & Mean & $\begin{array}{l}\text { Standard } \\
\text { deviation }\end{array}$ & $\mathrm{P}$ \\
\hline \multirow{2}{*}{ Gender } & Male & 54.4 & 7.35 & \multirow{2}{*}{0.29} \\
\hline & Female & 53 & 7.12 & \\
\hline \multirow{2}{*}{ Environment } & Urban & 53.9 & 7.61 & \multirow{2}{*}{0.91} \\
\hline & Rural & 54 & 7.02 & \\
\hline \multirow{5}{*}{ Age Group } & $<50$ & 51.6 & 6.755 & \multirow{5}{*}{0.56} \\
\hline & $50-59$ & 54.3 & 8.383 & \\
\hline & $60-69$ & 55.03 & 6.888 & \\
\hline & $70-79$ & 53.6 & 6.689 & \\
\hline & $>80$ & 54.6 & 7.789 & \\
\hline \multirow{4}{*}{ Tumor size } & $<1 \mathrm{~cm}$ & 54.15 & 7.376 & \multirow{4}{*}{0.47} \\
\hline & $1-2 \mathrm{~cm}$ & 53.12 & 7.359 & \\
\hline & $2-3 \mathrm{~cm}$ & 55.66 & 7.192 & \\
\hline & $>3 \mathrm{~cm}$ & 52.70 & 6.589 & \\
\hline
\end{tabular}

For LDL Cholesterol, mean values and standard deviation are represented in Table 5. From the analysis of the data, we observed that males have a higher average value (difference not statistically significant, $\mathrm{p}=0.19$ ), patients from rural and urban environment have approximately the same average values, with a higher dispersion for patients in urban area (difference is not statistically significant, $\mathrm{p}=0.78$ ). According to age, patients between 60 and 79 years old have the highest values for LDL Cholesterol, but there is no statistically significant difference $(\mathrm{p}=0.39)$. Tumor size, even if the values appear to have a higher average value as the tumor size grows, is not influencing the LDL Cholesterol values in a significant way $(p=0.51)$.

Table 5 LDL cholesterol

\begin{tabular}{|c|c|c|c|c|}
\hline \multicolumn{2}{|c|}{ LDL Cholesterol } & Mean & $\begin{array}{l}\text { Standard } \\
\text { deviation }\end{array}$ & $\mathrm{P}$ \\
\hline \multirow{2}{*}{ Gender } & Male & 124.71 & 124.71 & \multirow{2}{*}{0.19} \\
\hline & Female & 121.33 & 121.33 & \\
\hline \multirow{2}{*}{ Environment } & Urban & 123.34 & 14.84 & \multirow{2}{*}{0.78} \\
\hline & Rural & 123.99 & 13.50 & \\
\hline \multirow{5}{*}{ Ages } & $<50$ & 121.89 & 13.37 & \multirow{5}{*}{0.39} \\
\hline & $50-59$ & 120.09 & 15.11 & \\
\hline & 60-69 & 126.12 & 13.63 & \\
\hline & 70-79 & 126.07 & 11.33 & \\
\hline & 880 & 122.68 & 17.35 & \\
\hline \multirow{4}{*}{ Tumor size } & $<1 \mathrm{~cm}$ & 122.74 & 13.37 & \multirow{4}{*}{0.51} \\
\hline & $1-2 \mathrm{~cm}$ & 122.48 & 15.05 & \\
\hline & $2-3 \mathrm{~cm}$ & 127 & 13.38 & \\
\hline & $P 3 \mathrm{~cm}$ & 126 & 15.92 & \\
\hline
\end{tabular}


What is interesting is that, almost $40 \%$ of the female patients have LDL Cholesterol values above the normal limits (Figure 2).

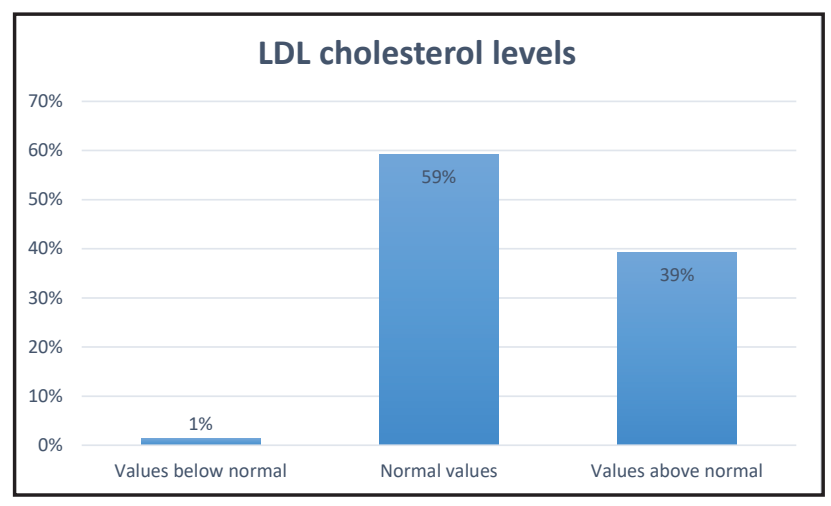

Figure 2 Analysis of the LDL indicator

\section{Discussions}

Regarding to male creatinine analysis, it is noted that $43 \%$ of patients have values below normal, indicating a glomerular filtration impairment, which may create a relative state of immunodeficiency that may influence the development of cancer (11). In men, $1.5 \%$ of the creatine stock is converted daily into creatinine. Food creatine (especially meat) increases creatine and creatinine. Reduction of protein intake decreases creatinine levels by the absence of arginine and glycine amino acids, creatine precursors (12).

Elevated urea levels beyond the normality limit may be due to prerenal causes, such as some mechanisms that work before glomerular filtration. One of these mechanisms is the effect of reducing renal blood flow due to diabetes mellitus or insipid diabetes. In addition, studies have shown that the incidence rate and the risk of developing BCC is significantly increased in adults with diabetes (13). Other causes of elevated values are renal (glomerular, tubular, vascular or intestinal disorders): acute renal failure (glomerulonephritis). Male HDL cholesterol values show a high percentage of $68 \%$ above normal. There are $32 \%$ of normal values, correlated with elevated LDL cholesterol, indicating a high atherogenic risk (10), confirming other studies showing that although serum LDL cholesterol levels were observed in patients with $\mathrm{BCC}$, there is still no statistically significant difference between patients and healthy individuals (14).

Cholesterol distribution in females shows that $59 \%$ of patients with BCC have possible hepatic impairment and high atherogenic risk factor.

A study of patients with different malignancies showed that total lipid, cholesterol and HDL cholesterol levels were inversely associated with the incidence of cancer (15). In women, HDL cholesterol values show a percentage of normal values of $41 \%$. And the values below the normality range are high (39\%) and the values above the normality threshold are $20 \%$. Thus, $59 \%$ of patients with $\mathrm{CBC}$ have hepatic impairment and high atherogenic risk factor.

\section{Conclusions}

Basel-cell epitheliomas are slow-growing tumors, usually non-metastatic but invasive. It develops from the primitive germ cells of the skin epithelium and especially of the skin annexes.

Regarding the male creatinine indicator, $49 \%$ of the patients show normal values, and $51 \%$ of patients have values below normal.

The urea indicator shows that most values do not exceed the normality threshold ( $84 \%)$, but $16 \%$ of the patients exceed the normality limit due to pre-renal causes.

For male cholesterol analysis the values do not show values below normal, but show a high percentage of $68 \%$ of values above normal values. There are $32 \%$ of normal values, correlated with elevated LDL cholesterol. The present study shows the non-correlation between this indicator and the basal cell carcinoma dimensions.

HDL cholesterol values show a percentage of normal values of $41 \%$. The values below the normality range are high (39\%) and the values above the normality threshold are $20 \%$. In conclusion, $59 \%$ of patients with BCC have hepatic impairment and high atherogenic risk factor.

Regarding the LDL indicator, LDL cholesterol is found to be between 59\% normal values and below these values in only $2 \%$. Above the limits of normality is $39 \%$. 


\section{References}

1. Kanitakis J. Anatomy, histology and immunohistochemistry of normal human skin. Eur J dermatology. 2002;12(4):390-9.

2. Kalinin AE, Kajava A V., Steinert PM. Epithelial barrier function: assembly and structural features of the cornified cell envelope. BioEssays [Internet]. 2002 Sep [cited 2017 Jan 8];24(9):789-800. Available from: http://www.ncbi.nlm.nih.gov/ pubmed/12210515

3. Harder J, Schröder J-M, Gläser R. The skin surface as antimicrobial barrier: present concepts and future outlooks. Exp Dermatol [Internet]. 2013 Jan [cited 2017 Jan 8];22(1):1-5. Available from: http://www. ncbi.nlm.nih.gov/pubmed/23088757

4. Marc Thiriet. Biomathematical and Biomechanical Modeling of the Circulatory and Ventilatory Systems. 2011. 34 p.

5. Vural P, Canbaz M, Sekçuki D MA. Lipid profile in actinic keratosis and basal cell carcinoma. Int J Dermatol. 1999;38(6):439-.

6. Giovannucci E, Harlan DM, Archer MC, Bergenstal RM, Gapstur SM, Habel LA, et al. Diabetes and cancer. Diabetes Care [Internet]. 2010;33(7):1674-85. Available from: http://www.ncbi.nlm.nih. gov/pubmed/20587728\%5Cnhttp://www. pubmedcentral.nih.gov/articlerender. fcgi?artid=PMC2890380

7. Leonard G, Nelu D-P, Sergiu C, Tony H, Natalia R, Olimpia M. Electron Microscopy Study of Nodular Basal Cell Carcinoma. ARS Medica Tomitana. 2018;24(2):90-5.

8. Gurgas L, Hangan T, Chirila S, Rosoiu N. Analysis methods of treatment as recurrent factor of basal cell carcinomas analysis methods of treatment as recurrent factor of basal cell carcinomas. Arch Balk Med Union [Internet]. 2016;51(3):347-51. Available from: http://umbalk.org/wp-content/ uploads/2016/12/2016-3-347.pdf

9. Gurgaş L, Hangan T, Chirilă S, Roşoiu N. Environment and gender influence the location of basal cell carcinoma. Acad Rom Sci Ann -Series Biol Sci [Internet]. 2016;5(1):64-72. Available from: http://
www.aos.ro/_new/AnaleOnline/Biologie/ BVol5Nr1Art.5.pdf

10. Gurgas L, Popescu ND, Hangan LT, Chirila S, Rosoiu N. The Evolution of Biochemical Indices After Basal Cell Epithelioma Removal - Case Report. ARS Medica Tomitana. 2017 Jan;23(2):99-104.

11. Lawrence L. Kidney Function May Affect Risk for Kidney, Bladder Cancer. cancer Netw home J Oncol. 2014;

12. Creatinină serică | Synevo [Internet]. [cited 2019 Jan 31]. Available from: https://www. synevo.ro/creatinina-serica/

13. Hui-Wen Tseng, Yow-Ling Shiue, KuoWang Tsai, Wei-Chun Huang, Pei-Ling Tang H-CL. Risk of skin cancer in patients with diabetes mellitus. Med [Internet]. 2016 [cited 2018 Nov 28];v.95(26); Available from: https://www.mendeley.com/library/

14. Abbas Zamanian, Ghasem Rahmatpour Rokni, Akram Ansar, Pezhman Mobasher and GAJ. Should variation of serum lipid levels be considered a risk factor for the development of basal cell carcinoma? Adv Biomed Res. 2014;3:108.

15. Raste AS, Naik PP. Clinical significance of lipid profile in cancer patients. Indian $\mathrm{J}$ Med Sci [Internet]. 2000;54(10):435-41. Available from: http://www.ncbi.nlm.nih. gov/pubmed/11262860 